\title{
Chemometric Match to Evaluate Fatty Acids Degradation of Animal and Plant Fats after Heating Treatment by Principal Component Research (PCR)
}

\author{
Nor Aishah Mohd Salleh, Mohd Sukri Hassan
}

\begin{abstract}
Fats have value demand of diet intake to supply energy and as cooking medium. Unsaturated fatty acids (UFAs) may prone to fatty acids (FAs) oxidation during heating process of fat by altering the double bonds between carbon atoms into trans fatty acids (TFAs) and saturated fatty acids (SFAs). TFAs and SFAs have been known as potential undesirable health effects for consumption. Thus monitoring the changes of oxidation UFAs at certain heat condition is essential to investigate the heat impact of various edible fats from animals and plants. The aim of the study was to evaluate FAs degradation various edible fats after heating treatments. The variety of fats such as chicken, beef, lard, mutton and plant fats were heated under controlled temperatures $\left(120,180\right.$ and $\left.240{ }^{\circ} \mathrm{C}\right)$ and hours of heating $(0.5,1,2$ and 3 hrs). FAs were profiled by combination of gas chromatography-flame ionization detector (GC-FID) and chemometrics techniques. The major FAs were identified after heating treatment such as Palmitic (C16:0), Stearic (C18:0), Elaidic (C18:1n9t), Oleic (C18:1n9c) and Linolelaidic (C18:2n6c). Observation through sum heat at $120^{\circ} \mathrm{C}$ $/ 3 \mathrm{hrs}, 180^{\circ} \mathrm{C} / 3 \mathrm{hrs}$ and $240^{\circ} \mathrm{C} / 2$ and $3 \mathrm{hr}$ contributed by SFAs and TFAs (C16:0, C18:0 and C18:1n9t) for all animal fats. The UFAs (C18:1n9c and C18:2n6c) contributed by sum heat of $120^{\circ} \mathrm{C} / 0.5-2 \mathrm{hrs}, 180{ }^{\circ} \mathrm{C} / 0.5-2 \mathrm{hrs}$ and $240^{\circ} \mathrm{C} / 0.5$ in a group. Plant fats were groups together by themselves and segregated from animal fats. These findings suggested that the degradation of UFAs to the SFAs and TFAs are related to the heat condition regardless species of animal fats.
\end{abstract}

Index Terms: Animal fats, fatty acids, heating treatments, principal component analysis.

\section{INTRODUCTION}

Animal fats are obtained from adipose tissues of animal fats and by-product of meat production. Only $4 \%$ of 2345 kiloton animal fats production was involved as edible fats for Europe population in 2011 [1]. For centuries, animal fats such as lard and tallow were used for baking ingredient especially in bakeries industry. For instants lard and tallow are occasionally used on a commercial scale to make pie crusts and butter is used in high quality applications such as puff pastries, croissants, and other laminated products. The use of animals fats have been substituted by shortening or hydrogenated plant fats from palm oils because of some religions concern and food regulator as Kosher, Halal and vegetarian practitioners.

Revised Manuscript Received on July 10, 2019.

Nor Aishah Mohd Salleh, Faculty of Science and Technology,

Universiti Sains Islam Malaysia (USIM), 71800 Bandar Baru Nilai, Negeri Sembilan, Malaysia.

Mohd Sukri Hassan, Faculty of Science and Technology, Universiti Sains Islam Malaysia (USIM), 71800 Bandar Baru Nilai, Negeri Sembilan, Malaysia.
The stability of oils and fats are great importance when used for cooking foods at elevated heats utilized during baking, frying, or roasting. The cooking process utilized heating process at certain temperatures and duration then oxidized fats into complex chemical secondary product such as ketones, aldehyde, alcohol, hydrocarbon, and free fatty acids through multiple mechanisms. Both thermal and oxidative reactions occur at an accelerating rate, causing oil deterioration continuously, thus affecting the fats by changing saturated FA (SFA) that no double bond of carbon and unsaturated FA (UFA), FA contains double bond. UFA is divided into 2 groups; polyunsaturated FA (PUFA) that contains more than 2 double bonds and monosaturated FA (MUFA) contain single double bonds. These FA groups are defined characterization and profile each different fats species. The heated UFA is enable to reconfigure cis isomer into trans FAs (TFAs) that suggested to be a product of partial hydrogenation [2], [3]. TFAs have been received an attention of researchers because it associated a harmful to the heath by linking the effect on low density lipoprotein cholesterol (LDL-c) and increasing the risk of cardiovascular heart disease [4]-[6].

UFA of lipid matrices protects plant sterols from degradation during heating treatment were evaluated at 180 ${ }^{\circ} \mathrm{C}$ for up to $180 \mathrm{~min}$ [7]. A comparative vacuum frying and convectional has showed that vacuums frying at $80 \mathrm{mmHg}$ (water boiling point: $42^{\circ} \mathrm{C}$ ) and oil temperature $\left(107^{\circ} \mathrm{C}\right.$ ) are determined to obtain an equivalent thermal driving force $\left(\Delta 65^{\circ} \mathrm{C}\right)$ of that of the atmospheric frying conditions used $\left(165^{\circ} \mathrm{C}\right)$ have significantly prevented degradation of PUFA [8]. Roasting caused the most pronounced increase of the SFA and decrease in the PUFA of heated pork muscles [9]. Algal oil has been suggested as alternative deep frying oils according to the highest physical and chemical stability during the frying process compared to sunflower and palm oils [10]. There were reductions of $21 \%$ and $38 \%$ in the total PUFA of the pan fried and cooked king mackerel samples [11]. Potatoes fried in corn oil is MUFA-rich oils tested had produce higher amounts of aldehydes derived from PUFA oxidation [12].

Despite the fact the FAs composition are known to be of fundamental importance of lipid oxidation, the relative magnitude of distribution FAs by heat condition have

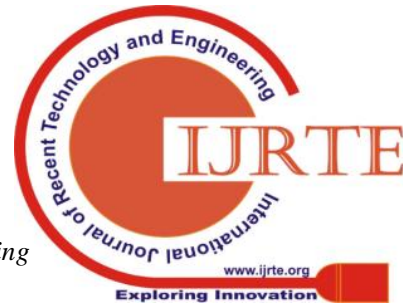




\section{CHEMOMETRIC MATCH TO EVALUATE FATTY ACIDS DEGRADATION OF ANIMAL AND PLANT FATS AFTER HEATING TREATMENT BY PRINCIPAL COMPONENT RESEARCH (PCR)}

proved elusive in different species animal fats. The association between SFA, MUFA and PUFA impact on oxidation is well documented, studies have usually demonstrated by the means and significant results on profiling FAs by total of groups such as SFA, MUFA and PUFA. TFAs are included in UFA groups and the profiling proposed to consider of individuals FAs. Sum of heating $\left({ }^{\circ} \mathrm{C} \mathrm{X}\right.$ hours) or sum heat could also affect the distribution of FAs. The multifactorial such as pressures, antioxidant and width of plates during the heat process can be affected the oxidation. Therefore heating treatments with controlled the temperatures and duration was designed to observe the trend of individuals and FAs by groups and ratios combination of both.

The aim of the study was to evaluate degradation FAs of animal fats after heating treatments for FAs profiling purposes. Chemometrics technique such principal component analysis (PCA) was applied to the data matrix of FAs obtained from GCFID. The relationship of heating treatments and changes individual FAs were explained by PCA. The evaluation of heating treatments to differs among a variety of animal fats and plant fats based on FAs data were observed. Findings of the research will be used for the nutrient database of various animals fats and plant fats after at certain ranges heating treatments that resemblance to the cooking condition and suitable for human consumption.

\section{MATERIALS AND METHODS}

\section{Samples and Heating Treatments}

A total of 5 types of fats, beef, chicken, lard, beef and plant fat- hydrogenating palm oil (HPO) were purchased at markets in Nilai, Malaysia. Animal fats were minced and weighted at $100 \mathrm{~g}(\mathrm{w} / \mathrm{w})$ and placed on hot digital in $250 \mathrm{ml}$ quartz beakers. Heating treatments were followed from the method [13]. The temperatures at $\left(120{ }^{\circ} \mathrm{C}, 180{ }^{\circ} \mathrm{C}\right.$ and 240 ${ }^{\circ} \mathrm{C}$ ) were controlled probes contacted into fat tissues. Durations of heating were selected at $0.5,1,2$ and 3 hours. Shortening is selected as controlled fats samples due to $\beta$ ' (beta primer) crystalized as a solid at room temperatures that have similar physical characters as extracted animal fats. Approximately $20 \mathrm{ml}$ aliquot of heated oils were collected and cooled at room temperatures before kept into universal bottle and refrigerated at $4{ }^{\circ} \mathrm{C}$.

Table 1: Heating treatments of animal and plant fats [13]

\begin{tabular}{|c|c|c|c|c|c|c|c|c|}
\hline No. & $\begin{array}{c}\mathrm{T} \\
\left({ }^{\circ} \mathrm{C}\right)\end{array}$ & $\begin{array}{c}\text { Hours } \\
(\mathrm{hrs})\end{array}$ & $\begin{array}{c}\text { Sum Heat } \\
\left({ }^{\circ} \mathrm{C}\right) \times(\mathrm{hrs})\end{array}$ & $\begin{array}{c}\text { Beef } \\
\text { Fat (B) }\end{array}$ & $\begin{array}{c}\text { Chicken } \\
\text { Fat (C) }\end{array}$ & $\begin{array}{c}\text { Lard } \\
(\mathrm{L})\end{array}$ & $\begin{array}{c}\text { Mutton } \\
\text { Fat (M) }\end{array}$ & $\begin{array}{c}\text { Plant } \\
\text { Fat (V) }\end{array}$ \\
\hline 1 & 120 & 0.5 & 60 & B-01 & C-01 & L-01 & M-01 & V-01 \\
\hline 2 & 120 & 1 & 120 & B-02 & C-02 & L-02 & M-02 & V-02 \\
\hline 3 & 120 & 2 & 240 & B-03 & C-03 & L-03 & M-03 & V-03 \\
\hline 4 & 120 & 3 & 360 & B-04 & C-04 & L-04 & M-04 & V-04 \\
\hline 5 & 180 & 0.5 & 90 & B-05 & C-05 & L-05 & M-05 & V-05 \\
\hline 6 & 180 & 1 & 180 & B-06 & C-06 & L-06 & M-06 & V-06 \\
\hline 7 & 180 & 2 & 360 & B-07 & C-07 & L-07 & M-07 & V-07 \\
\hline 8 & 180 & 3 & 540 & B-08 & C-08 & L-08 & M-08 & V-08 \\
\hline 9 & 240 & 0.5 & 120 & B-09 & C-09 & L-09 & M-09 & V-09 \\
\hline 10 & 240 & 1 & 240 & B-10 & C-10 & L-10 & M-10 & V-10 \\
\hline 11 & 240 & 2 & 480 & B-11 & C-11 & L-11 & M-11 & V-11 \\
\hline 12 & 240 & 3 & 720 & B-12 & C-12 & L-12 & M-12 & V-12 \\
\hline
\end{tabular}

\section{Fatty Acids Profiling}

After heat treatments fats were extracted to remove tissue residuals using [14]. Then, fatty acids methyl ester were performed by using method AOAC [15] by using methanolic hydrogen chloride $5 \%$ as a catalyst. The methyl esters were determined an Agilent Technologies 7890N Network gas chromatograph system with FID detector (Agilent Technologies USA) was employed for FAs analysis. Operating conditions were as follows: the column was a column: BPX90, with length $60 \mathrm{~m} \times 0.25 \mathrm{~mm}$ I.D. df: 0.25 $\mu \mathrm{m}$. Column temperature was set at $140{ }^{\circ} \mathrm{C}$ and increasing into $260{ }^{\circ} \mathrm{C}$ at $5{ }^{\circ} \mathrm{C} / \mathrm{min}$. The $\mathrm{GC}$ condition were used helium as the carrier gas with flow rate $25 \mathrm{~cm} / \mathrm{sec}$ and spilt ratio $1: 25$ with detector temperatures $250{ }^{\circ} \mathrm{C}$.
The obtained chromatogram of FAs using Chemstation (USA) software version 5.2 and quantified on basis known retention time from standard 37 FAME Mix from the Supelco (USA).

\section{CHEOMETRIC TECHNIQUE}

A total of $60 \times 25$ matrices of edible fats and FAs were normalized by area before subjected to Principal Component Analysis (PCA). PCA was performed by using Unscrambler software (X10.2). The multivariate data set of FAMEs are represent as relative percentages of FAs were subjected to PCA in order to reduce the data set to scores and loadings

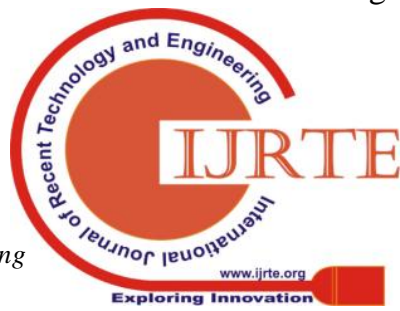


matrices that determined by as principal component (PC). The calculation of PC as per equation (1) below;

$$
P C=a_{1}\left(\frac{x_{1}-\mu}{\frac{\sigma}{\sqrt{n}}}\right)
$$

where $a_{1}$ is a loading of linear transformation, $x_{1}$ is measurements of raw FAs value, $\mu$ is mean value for FAs, $\sigma$ $\mathrm{s}$ standard deviations of FAs and $\mathrm{n}$ is total of samples FAs.

\section{RESULTS AND ANALYSIS}

\section{Fatty Acids Profiles}

An illustrative GC chromatogram of the FAME from animal fats is showed in Fig. 1. A total of 22 FAs of various heated fats containing 2 trace $(>0.1 \%)$ of FAs were identified by retention time of external standard $37 \mathrm{mix}$ of FAMEs. Data matrix of 60 samples and 21 FAs were compressed into the box plot (Fig. 2).

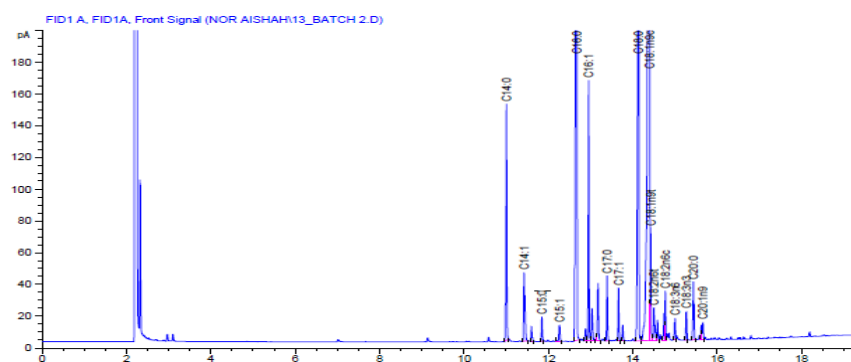

Fig. 1: A chromatogram of FAs chicken fats after heat treatment at $\left(120^{\circ} \mathrm{C} / 1 \mathrm{hrs}\right)$ by GC-FID

This box plot shows the summary of the distributions of the FAs (Fig. 2). It shows the total range of variation of each variable. The box plot revealed in fatty acids the largest concentration variation in the experiment. This plot contains one Box-plot for each variable, either over the whole sample set. It shows the minimum, the $25 \%$ percentile (lower quartile), the median, the $75 \%$ percentile (upper quartile) and the maximum. The box plot revealed 8 FAs with different variation; C14:0 (0-3.88), C16:0 (19.43-64.98), C16:1 (0-6.93), C18:0 (3.99-36.30), C18:1n9t 0-4.33), C18:1n9c (0-37.86), C18:2n6t (0-2.68), C18:2n6c (0-23.88) and $\mathrm{C} 18: 3 \mathrm{n} 3(0-3.44)$. The extremes values showed at FA $\mathrm{C} 16: 0$ and $\mathrm{C} 18: 0$ represents quartiles $75 \%$ suggested that fats have high differentiation

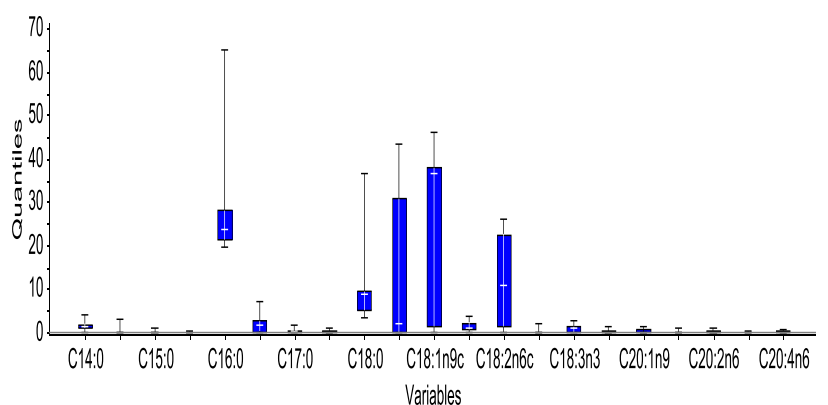

Fig. 2: Box plot of variables (FAs) from 60 edibles fats after heat treatment
From the variation of FAs (variables) the data are suggested to transform by area normalization. Normalization of data will be organized the FAs to minimize data redundancy of the small amount of values such C14:015:1 and C18:3n6-C20:4n6 FAs areas.

Pearson correlation coefficient between FAs variation are given in the Table 2. The correlation between Elaidic (C18:1n9t) with Oleic acid (C18:1n9c) and Linoleic C18:2n6c FAs was strong but negative $(r=-0.97, \mathrm{p}<0.05)(\mathrm{r}$ $=-0.97, \mathrm{p}<0.63)$ which means that the increase in one FA leads to a corresponding decrease in other. This negative relationship originates from heat treatments. In the other side palmitic acid (C16:0) are positive correlated to Elaidic $(\mathrm{r}=0.58, \mathrm{p}<0.05)$ and negative correlated $(\mathrm{r}=0.65, \mathrm{p}$ $<0.05)$ to Oleic $(\mathrm{C} 18: 1 \mathrm{n} 9 \mathrm{c})$. Linoleic acid indicated positive correlation between $\mathrm{C} 18: 2 \mathrm{n} 6 \mathrm{t}(\mathrm{r}=0.52, \mathrm{p}<0.05)$ and $\mathrm{C} 18: 2 \mathrm{n} 6 \mathrm{c}(\mathrm{r}=0.61, \mathrm{p}<0.05)$.

Table 2: Pearson correlation coefficient between percentage levels of six FAs from heat treatments of animal fats and palm fats (HVO)

\begin{tabular}{|c|c|c|c|c|c|c|}
\hline & $\mathrm{C} 16: 0$ & $\mathrm{C} 18: 0$ & $\mathrm{C} 18: 1 \mathrm{n} 9 \mathrm{t}$ & $\begin{array}{c}\mathrm{C} 18: 1 \\
\mathrm{n} 9 \mathrm{c}\end{array}$ & $\begin{array}{c}\mathrm{C} 18: 2 \\
\mathrm{n} 6 \mathrm{t}\end{array}$ & $\mathrm{C} 18: 2 \mathrm{n} 6 \mathrm{c}$ \\
\hline $\mathrm{C} 16: 0$ & 1 & -0.36 & 0.58 & -0.65 & -0.49 & -0.45 \\
\hline $\mathrm{C} 18: 0$ & -0.36 & 1 & 0.15 & -0.17 & -0.21 & -0.46 \\
\hline $\mathrm{C} 18: 1 \mathrm{n} 9 \mathrm{t}$ & $0.58^{*}$ & 0.15 & 1 & -0.97 & -0.49 & -0.63 \\
\hline $\mathrm{C} 18: 1 \mathrm{n} 9 \mathrm{c}$ & $-0.65^{*}$ & -0.17 & $-0.97^{*}$ & 1 & 0.52 & 0.61 \\
\hline $\mathrm{C} 18: 2 \mathrm{n} 6 \mathrm{t}$ & -0.49 & -0.21 & -0.49 & $0.52^{*}$ & 1 & 0.57 \\
\hline $\mathrm{C} 18: 2 \mathrm{n} 6 \mathrm{c}$ & -0.45 & -0.46 & $-0.63^{*}$ & $0.61^{*}$ & $0.57 *$ & 1 \\
\hline
\end{tabular}

*symbols corresponds the significant values at the level significance $\alpha=0.05$ (two tailed test).

\section{Principal Component Analysis (PCA)}

The data matrix of the predominant of FAs in heated edible fats was subjected to PCA to decrease the numbers of descriptors (variables) associated with the data set, while still explaining maximum amount of variability in the data. Table 3 shows the most significant PCs generated from the FAs and their loadings. Eigenvalues are total of loadings plot (FAs) that mapping scores plot (samples of edibles fats). The first PC-1 had the highest eigenvalue of 7.34, accounted $73.7 \%$ of the variability in the data set. The second PC-2 had eigenvalue of 1.57, accounted for $15.5 \%$ and total PC-1 and PC-2 cumulative at $89.2 \%$ explained the variances. The following three PCs less than 1 eigenvalues are considered as non-informative for this model [16]. 
CHEMOMETRIC MATCH TO EVALUATE FATTY ACIDS DEGRADATION OF ANIMAL AND PLANT FATS AFTER HEATING TREATMENT BY PRINCIPAL COMPONENT RESEARCH (PCR)

Table 3: Eigenvalue and the percentages of the variance and cumulative of the data matrix after subjected to PCA

\begin{tabular}{|c|c|c|c|c|c|c|c|}
\hline & PC-1 & PC-2 & PC-3 & PC-4 & PC-5 & PC-6 & PC-7 \\
\hline Eigenvalues & 7.34 & 1.57 & 0.75 & 0.24 & 0.03 & 0.01 & 0.01 \\
\hline Variance (\%) & 73.7 & 15.49 & 2.98 & 0.59 & 0.3 & 0.17 & 0.11 \\
\hline Cumulative (\%) & 73.7 & 89.19 & 18.47 & 3.57 & 0.89 & 0.46 & 0.27 \\
\hline
\end{tabular}

Fig. 3 shows two graphs of the representation of samples scores in the first two principal components (PC-1 vs. PC2). In order to emphasis each sample by using different treatments; in the first plot (3a), it is shown the scores plot of the grouping samples fats, in the loading plot (3b), possible outline is proposed FAs. Heating treatments at different temperatures are representations with colors

regardless of their duration heating.

Fig. 3 shows two graphs of the representation of samples scores in the first two principal components

(PC-1 vs. PC-2). In order to emphasis each sample by using different treatments; in the first plot (3a), it is shown the scores plot of the grouping samples fats, in the loading plot (3b), possible outline is proposed FAs. Heating treatments at different temperatures are representations with colors regardless of their duration heating.

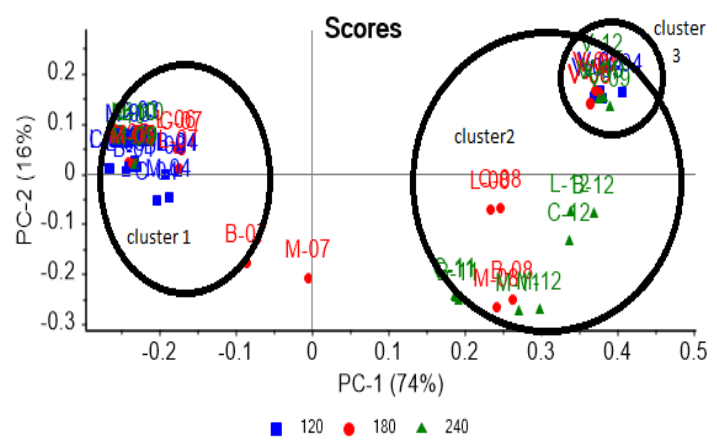

(a)

Observation has been labeled by colors however, there are integration among highest $\left(240{ }^{\circ} \mathrm{C}\right)$ temperatures with the lowest ones $\left(120^{\circ} \mathrm{C}\right)$ in the scores plot. It is reasonable because each samples treated at that different duration hours effected together with heating temperatures. Therefore, sum heat from multiplying temperatures and duration time $\left({ }^{\circ} \mathrm{C}\right) \mathrm{x}$ (hrs) are the best parameter to represent the heat treatments.

The scores plots show the details of samples that belong to clusters. The samples were rearranged according the sum heat and clusters (Table 4). Cluster 1 starting from No. 1-12 shows the mixtures of animal fats at range of sum heat 480 720 and represents the highest level heat treatments of models and cluster 2 starting from No. 13-48 shows the mixtures of animals fats at range of sum heat 60-360 and represents the lowest level of heat treatments. Clusters 3 are represent all samples from plant fats (V) in one group (No. 49-60). Heat treatments by sum heat follow descending according the clusters of animal fats.

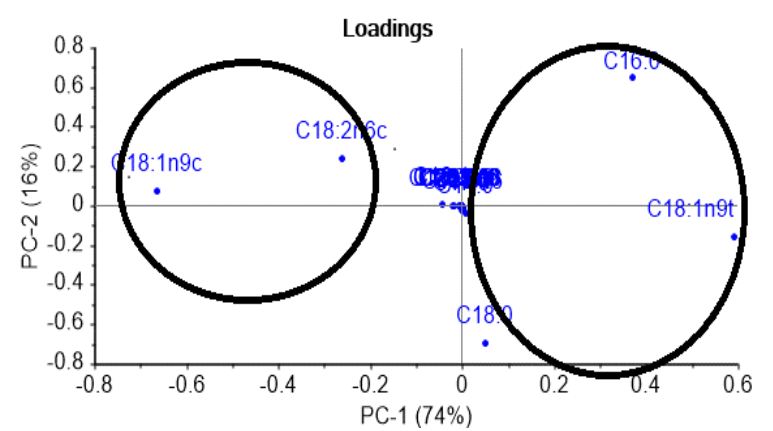

(b)

Fig. 3: PCA models of 5 type edibles fats after the heating treatments. (a) Scores plot represent edibles fats.

Label: $C=$ chicken fat, $B$ = beef fats, $L=$ lard, $M=$ mutton fats and $\mathrm{V}=$ plant fats (HVO). (b) Represent of FAs (C16:0), Stearic (C18:0), Elaidic (C18:1n9t), Oleic (C18:1n9c) and Linoleic (C18:2n6c)

There are three clusters can be identified from scores plot (Fig. 3a). 1st clusters mostly located at positive PC-2. 2nd clusters located at positive PC-1. There are 2 samples M7 and $\mathrm{B} 7$ in between 2 clusters are checks belong to cluster 1 . The 3rd clusters are belonged to plant fats only. Clusters 2 and 3 are anti-correlated to cluster 1 and this is suggested that clusters 2 and 3 sharing same FAs but have major different to cluster 1. Samples of heated fats are closed together and the details only can identified by observing the scor plot table (Table 4).

Loadings plot (Fig. 3b) of FAs represents 5 major FAs C18:1n9c, C18:2n6c, C18:0, C18:1n9t and C16:0. FAs C18:1n9c, C18:2n6c located at positive side of PC-2 and both FAs are in UFA groups with cis isomer and can be suggested represent of cluster 1. C18:0, C18:1n9t and C16:0 located anti correlated that can be suggested represent of cluster 2 and 3. C18:0 and C16:0 are in SFA groups. The $\mathrm{C} 18: \ln 9 \mathrm{t}$ is trans isomers or TFAs. For confirmation the by observing loadings plot at Table 5, it can be concluded only $\mathrm{C} 18: 2 \mathrm{n} 6 \mathrm{c}$ are less than 0.5 , concluded the FAs may represent average value but in point of view PC-1 vs. PC-2, this FAs belong to positive PC-2. 
Table 5: Loadings plot of the Fas

\begin{tabular}{|c|c|c|}
\hline FAs & PC-1 & PC-2 \\
\hline C16:0 & 0.37 & $0.65^{*}$ \\
\hline C18:0 & 0.05 & $-0.70^{*}$ \\
\hline C18:1n9t & $0.59^{*}$ & -0.16 \\
\hline C18:1n9c & $-0.66^{*}$ & 0.07 \\
\hline C18:2n6c & -0.26 & 0.24 \\
\hline
\end{tabular}

*Values > 0.5. FAs abbreviations: (C16:0), Stearic (C18:0), Elaidic (C18:1n9t), Oleic $(\mathrm{C} 18: \ln 9 \mathrm{c}), \quad$ Linolelaidic (C18:2n6t) and Linoleic (C18:2n6c).

\section{DISCUSSION}

The correlation from loading matrix revealed $\mathrm{PC}-1$ mainly contributed from Elaidic (C18:1n9t), Oleic $(\mathrm{C} 18: 1 \mathrm{n} 9 \mathrm{c})$, with anti-correlated each other. It is suggested that the decreasing of oleic acids will be increasing the Elaidic FAs. This trend explained by changes of heat sum from low to high has affected both FAs.

The relationship of Palmitic (C16:0) and Stearic (C18:0) FAs also anti-correlated each other by explained different type of animals fats and HPO, that the Stearic FA is presence abundance in the animal fats. The Palmitic FAs naturally found in some animal products like meat and dairy, as well as in palm and coconut oils [17].

From the results of raw data, Palmitic FA is abundance hydrogenating palm oil (HPO) than the others fats. But researches have been pronounced that consumption of Palmitic acid increases the risk of developing cardiovascular disease, based on studies indicating that it may increase LDL levels in the blood. Higher dietary intakes of major SFAs are associated with an increased risk of coronary heart disease [18], [19]

The hydrogenated process palm fat increased the percentages of palmitic acid in order to make this fats stabile and resistance against to oxidation [20]. It can be explained by scores plot of palm fats (V) grouping closely together due to temperatures resistances. Elaidic FA (18:1n9t) is the predominant TFA found in many partially hydrogenated fats and is produced in the deodorization of vegetable oils. The high level sum heat on animal fats and palm fats have correlation pattern through scores plot from distribution of respective FAs.

\section{CONCLUSION}

Study indicates that the combination FAs data analysis along with chemometrics (PCA) can successfully employed to give more information of SFA and UFA of edibles fats after heating treatments. Sum heat was suggested heating treatments parameters to evaluate the changes of FAs animal and plant fats. High level of sum heat was correlated to the undesirable FAs animal fats for human consumption.

\section{ACKNOWLEDGMENT}

The research financial was fully supported by Ministry of Higher Education of Malaysia under Fundamental Research Grant Scheme (FRGS) No. 50715 - Universiti Sains Islam Malaysia.

\section{REFERENCES}

1. A. M. Marín, P. Gómez-Cortés, A. G. Castro, M. Juárez, L. P. Alba, M. P. Hernández, and M. A. De la Fuente, "Animal performance and milk fatty acid profile of dairy goats fed diets with different unsaturated plant oils," Journal of Dairy Science, 94(11), 2011, pp. 5359-5368.

2. Y. Chen, Y. Yang, S. Nie, X. Yang, Y. Wang, M. Yang, C. Li, and M. Xie, "The analysis of trans fatty acid profiles in deep frying palm oil and chicken fillets with an improved gas chromatography method," Food Control, 44, 2014, pp. 191-197.

3. Y. Wang, T. Hui, Y. W. Zhang, B. Liu, F. L. Wang, J. K. Li, B. W. Cui, X. Y. Guo, and Z. Q. Peng, "Effects of frying conditions on the formation of heterocyclic amines and trans fatty acids in grass carp (Ctenopharyngodonidellus)," Food Chemistry, 167, 2015, pp. 251-257.

4. S. K. Gebauer, F. Destaillats, F. Dionisi, R. M. Krauss, and D. J. Baer, "Vaccenic acid and trans fatty acid isomers from partially hydrogenated oil both adversely affect LDL cholesterol: A double-blind, randomized controlled trial-3," American Journal of Clinical Nutrition, 102(6), 2015, pp. 1339-1346.

5. R. Ganguly, and G. N. Pierce. "The toxicity of dietary trans fats," Food and Chemical Toxicology, 78, 2015, pp. $170-176$.

6. L. Hooper, C. D. Summerbell, R. Thompson, D. Sills, F. G. Roberts, H. J. Moore, and G. D. Smith, "Reduced or modified dietary fat for preventing cardiovascular disease," Sao Paulo Medical Journal, 134(2), 2016, pp. 182-183.

7. B. Barriuso, I. Astiasarán, and D. Ansorena, "Unsaturated lipid matrices protect plant sterols from degradation during heating treatment," Food Chemistry, 196, 2016, pp. 451-458.

8. I. Albertos, A. B. Martin-Diana, I. Jaime, A. M. Diez, and D. Rico, "Protective role of vacuum vs. atmospheric frying on PUFA balance and lipid oxidation," Innovative Food Science and Emerging Technologies, 36, 2016, pp. 336-342.

9. P. Janiszewski, E. Grześkowiak, D. Lisiak, B. Borys, K. Borzuta, E. Pospiech, and E. Poławska, "The influence of thermal processing on the fatty acid profile of pork and lamb meat fed diet with increased levels of unsaturated fatty acids," Meat Science, 111, 2016, pp. 161-167.

10. A. Waghmare, S. Patil, J. G. LeBlanc, S. Sonawane, and S. S. Arya, "Comparative assessment of algal oil with other vegetable oils for deep frying," Algal Research, 31, 2018, pp. 99-106.

11. G. M. Lira, C. C. Cabral, I. B. de Oliveira, B. C. Figueirêdo, S. J. Simon, and N. Bragagnolo, "Changes in the lipid fraction of king mackerel pan fried in coconut oil and cooked in coconut milk," Food Research International, 101, 2017, pp. 198-202.

12. C. S. Santos, L. Molina-Garcia, S. C. Cunha, and S. Casal, "Fried potatoes: Impact of prolonged frying in monounsaturated oils," Food Chemistry, 243, 2018, pp. 192-201.

13. N. A. Salleh, M. S. Hassan, J. Jumal, F. W. Harun, and M. Z. Jaafar, "Differentiation of edible fats from selected sources after heating treatments using fourier transform infrared spectroscopy (FTIR) and multivariate analysis," AIP Conference Proceedings, 1972(1), 2018, pp. 1-8.

14. J. Folch, M. Lees, and G. H. S. Stanley, "A simple method for the isolation and purification of total lipides from animal tissues," J biol Chem., 226(1), 1957, pp. 497-509. 


\section{CHEMOMETRIC MATCH TO EVALUATE FATTY ACIDS DEGRADATION OF ANIMAL AND PLANT FATS AFTER HEATING TREATMENT BY PRINCIPAL COMPONENT RESEARCH (PCR)}

15. AOAC Official Method 963.22, "Methyl esters of fatty acids in oil and fats gas chromatographic method," AOAC Official Methods Anal., 41, 1995, pp. 18-21.

16. H. F. Kaiser, "The varimax criterion for analytic rotation in factor analysis," Psychometrika, 23(3), 1958, pp. 187200.

17. I. N. Aini, and M. S. Miskandar, "Utilization of palm oil and palm products in shortenings and margarines," European Journal of Lipid Science and Technology, 109(4), 2007, pp. 422-432.

18. G. Zong, Y. Li, A. J. Wanders, M. Alssema, P. L. Zock, W. C. Willett, F. B. Hu, and Q. Sun, "Intake of individual saturated fatty acids and risk of coronary heart disease in US men and women: Two prospective longitudinal cohort studies," British Medical Journal, 355, 2016, pp. 1-11.

19. R. J. De Souza, A. Mente, A. Maroleanu, A. I. Cozma, V. Ha, T. Kishibe, E. Uleryk, P. Budylowski, H. Schünemann, J. Beyene, and S. S. Anand, "Intake of saturated and trans unsaturated fatty acids and risk of all cause mortality, cardiovascular disease, and type 2 diabetes: Systematic review and meta-analysis of observational studies," British Medical Journal, 351, 2015, pp. 1-16.

20. O. I. Mba, M. J Dumont, and M. Ngadi, "Palm oil: Processing, characterization and utilization in the food industry-A review," Food Bioscience, 10, 2015, pp. 2641. 